\title{
Optimizing the synthesis of carbon nanofiber based electrocatalysts for fuel cells
}

David Sebastián $^{\mathrm{a}}$, Isabel Suelves ${ }^{\mathrm{a}}$, Rafael Moliner ${ }^{\mathrm{a}}$, María Jesús Lázaro*a ${ }^{\text {, Alessandro }}$ Stassi $^{\mathrm{b}}$, Vincenzo Baglio ${ }^{\mathrm{b}}$, Antonino Salvatore Aricò ${ }^{\mathrm{b}}$

${ }^{a}$ Instituto de Carboquímica, CSIC, Miguel Luesma Castán 4, 50018, Zaragoza, Spain.

${ }^{b}$ Istituto di Tecnologie Avanzate per l'Energia "Nicola Giordano", CNR, Via Salita S. Lucia Sopra Contesse 5, Messina, Italy. Fax: +39090 624247; Tel: +39090624237

* Corresponding author: María Jesús Lázaro, Instituto de Carboquímica, CSIC, Miguel Luesma Castán 4, 50018, Zaragoza, Spain. Fax: +34 976733318; Tel: +34 976733977;

E-mail:mlazaro@icb.csic.es 


\begin{abstract}
This work deals with an optimization of the platinum dispersion on low surface area carbon nanofibers (CNFs) by using different synthesis procedures and its electrocatalytic activity towards oxygen reduction. The selected CNFs were characterized by a BET surface area of ca. $100 \mathrm{~m}^{2} \mathrm{~g}^{-1}$ and were in-house synthesized by the decomposition of $\mathrm{CH}_{4}$ at $700^{\circ} \mathrm{C}$. Pt nanoparticles were deposited by using four different synthesis routes. A metal concentration of $20 \mathrm{wt} \%$ was confirmed by EDX and TGA. Two classical impregnation routes were employed, one using $\mathrm{NaBH}_{4}$ as reducing agent at $15^{\circ} \mathrm{C}$ and the second one using formic acid at $80^{\circ} \mathrm{C}$. Two alternative processes consisted in a microemulsion procedure followed by reduction with $\mathrm{NaBH}_{4}$ and a colloidal route by using the sulphite complex method followed by reduction with hydrogen. The main differences regarded the platinum crystal size varying from $2.5 \mathrm{~nm}$ for the colloidal route to $8.1 \mathrm{~nm}$ for the impregnation route (formic acid). The classical impregnation procedures did not result appropriate to obtain a small particle size in the presence of this support, whereas microemulsion and colloidal methods fit the requirements for the cathodic oxygen reduction reaction in polymer electrolyte fuel cells, despite the low surface area of CNFs. The catalysts were subjected to an accelerated degradation test by continuous potential cycling. Although the initial activity was the highest for the microemulsion based catalyst, after the accelerated degradation test the colloidal based catalyst experienced a relatively lower loss of performance.
\end{abstract}

Keywords: carbon nanofibers supports, durability, fuel cells, oxygen-reduction reaction, platinum 


\section{Introduction}

Carbon nanostructures, including graphene, carbon nanotubes (CNTs) or carbon nanofibers (CNFs), have received much attention for a large number of applications due to their good properties at the nanoscale [1-5]. In particular, CNFs have received much less attention than CNTs because the latter present better theoretical properties due to a lower level of microstructural defects, higher tensile strength, smaller dimensions and lower density than CNFs. However, CNFs represent an excellent alternative because their production process can be easily transferable to the industry, and as a result, CNFs are about 2-3 times cheaper than multi-walled carbon nanotubes (MWNTs). Single wall carbon nanotubes (SWNTs) are even more expensive [6]. In addition, CNFs can be used for research purposes to build knowledge that might be transferable to the more expensive CNTs.

Mesoporous structure, highly graphitic character and resilience to corrosion are the main reasons to prefer carbon nanofibers over conventional supports based on carbon blacks for low temperature fuel cell applications. Fuel cell electrocatalysts are yet the main concern towards the commercialization of the fuel cell technology [7-13]. However, one of the drawbacks of CNFs is their relatively low surface area (lower than $200 \mathrm{~m}^{2} \mathrm{~g}^{-1}$ ), hindering an appropriate dispersion of platinum nanoparticles for the relatively high metal concentrations required in practical fuel cell electrodes (20-60 wt.\%) $[14,15]$. Fuel cell electrodes typically need catalysts with a high concentration of metal (platinum based) on the support to obtain a thin catalyst layer with large density of catalytic sites which is required to minimize ohmic drop and mass transfer limitations [16]. However, at the same time it is mandatory to maintain a good dispersion of small metal particles and a good resistance to corrosion phenomena for the catalyst.

Electrochemical corrosion is strongly related to surface area and the occurrence of defects in the graphitic structure. In this regard, it is important to individuate proper preparation procedures capable to achieve good metal dispersion on low surface area supports as well as to enhance the stability of the metallic phase towards sintering and dissolution [17]. 
The general aim of this work was to compare different preparation methods in relation to their ability to tailor physico-chemical and electrochemical properties of CNF supported Pt catalysts for oxygen reduction in low temperature fuel cells.

The specific objective of this work was to optimize the catalyst preparation on low surface area carbon nanofibers. Accordingly, in-house synthesized carbon nanofibers were prepared at a relatively high temperature $\left(700^{\circ} \mathrm{C}\right)$, which is known to favor the crystallinity and conductivity of the CNFs but hinders the development of a high porosity. The as-grown CNFs are hydrophobic. This aspect limits the application of aqueous based preparation methods for the deposition of $\mathrm{Pt}$ such as the impregnation procedures. The use of such procedures requires the introduction of surface oxygen groups on the support [18]. CNFs were thus treated with a mixture of concentrated nitric and sulfuric acids to increase the surface oxygen groups in order to favor the adsorption of the platinum precursor in the impregnation based catalyst synthesis [19-20]. 


\section{Experimental details}

\subsection{Synthesis of carbon nanofiber-supported platinum catalysts}

CNFs were grown according to a procedure previously reported [22]. These were treated with a mixture of concentrated nitric and sulfuric acids at room temperature during 30 minutes to increase the amount of surface oxygen groups.

Electrocatalysts based on platinum supported on carbon nanofibers were synthesized by four different routes, typically used to prepare similar nanosized Pt particles on carbon blacks supports. Among the high number of methods reported in literature for $\mathrm{Pt}$ catalyst synthesis the chosen ones are known to lead to appropriate particle size and dispersion for conventional supports. Impregnation procedures include a first step where the carbon support is dispersed in an aqueous solution. In order to favor carbon dispersion and consequently facilitate the dispersion of the active phase on the support surface, treated CNFs were used. Whereas, pristine CNFs were used for microemulsion and colloidal procedures.

Impregnation and reduction with formic acid (IFA) was carried out following the procedure described by Lizcano-Valbuena and co-workers [28]. It consisted in the addition of $\mathrm{H}_{2} \mathrm{PtCl}_{6}$ aqueous solution to the treated carbon nanofibers (fCNF), previously dispersed in a $2 \mathrm{M}$ formic acid solution under sonication. The slow addition of the metallic precursor took place under continuous stirring and at $80^{\circ} \mathrm{C}$. The catalyst was left overnight under continuous stirring and subsequently subjected to filtering and washing procedures with deionized water, to be finally dried at $60^{\circ} \mathrm{C}$ overnight.

The second impregnation procedure involved the reduction with sodium borohydride (ISB), as described by Salgado and co-workers [29]. Briefly, the treated carbon nanofibers (fCNF) were dispersed in ultrapure water under sonication for one hour. The $\mathrm{pH}$ of the dispersion of fCNFs in water was then adjusted to 5.0. An aqueous solution of $3 \mathrm{mM} \mathrm{H} \mathrm{H}_{2} \mathrm{PtCl}_{6}$ was prepared by high purity reagents (Sigma Aldrich) in ultrapure water (Milli-Q). Then the $\mathrm{H}_{2} \mathrm{PtCl}_{6}$ aqueous solution was added dropwise to the support dispersion under sonication. The reduction took place by adding a $25 \mathrm{mM}$ sodium borohydride $\left(\mathrm{NaBH}_{4}\right.$, Sigma Aldrich) solution in ultrapure water (Milli-Q) at $15^{\circ} \mathrm{C}$ under sonication. The catalyst was left overnight under continuous stirring and 
subsequently subjected to filtering and washing procedures with deionized water, to be finally dried at $60^{\circ} \mathrm{C}$ overnight.

The third approach consisted in using a 'water in oil' microemulsion (MIC) with the aim of controlling the metallic particle size [30, 31]. Briefly, it consisted of the preparation of a microemulsion composed by $16.5 \%$ surfactant (polyethylene glycol dodecyl ether, Brij ${ }^{\circledR 30}$, Sigma-Aldrich), 3.9\% acqueous solution containing the platinum precursor $\left(50 \mathrm{mM} \mathrm{H}_{2} \mathrm{PtCl}_{6}\right)$ and $79.6 \%$ n-heptane as the hydrophobic phase. Subsequently, the appropriate amount of support was dispersed in the microemulsion under sonication to achieve a metal concentration in the catalyst of $20 \mathrm{wt} . \%$. The reduction step involved a slow addition of sodium borohydride in excess and finally the catalyst was thoroughly washed with ethanol and water to remove the chemicals used during the synthesis, and dried overnight at $60^{\circ} \mathrm{C}$.

A colloidal procedure (COL) to prepare $\mathrm{Pt} / \mathrm{CNF}$ catalysts with metal concentration of 20 wt.\% on CNFs was also used [32]. Sulphite complexes of Pt, in appropriate amounts, were decomposed by hydrogen peroxide to form aqueous colloidal solutions of Pt oxides. These particles were adsorbed on CNFs. The amorphous oxides on CNFs were thus reduced in a hydrogen stream to form metallic particles. The reduction process was considered complete when no significant $\mathrm{H}_{2}$ consumption was detected in the outlet stream by using a thermal conductive detector (TCD).

\subsection{Characterization techniques}

High-resolution transmission electron microscope (HRTEM) micrographs for the carbon nanofibers and the catalyst samples were obtained using a JEOL-2000 FXII microscope at $200 \mathrm{kV}$ and a spatial resolution of $0.28 \mathrm{~nm}$. To obtain the micrographs, the catalyst samples were finely grinded and ultrasonically dispersed in ethanol. A drop of the resultant dispersion was deposited and dried onto a standard copper grid coated with Lacey carbon.

X-Ray Diffraction patterns were performed using a Bruker AXS D8 Advance diffractometer, using $\mathrm{Cu}-\mathrm{K} \alpha$ radiation. Crystallite sizes were calculated from the Scherrer's equation on the (002) peak for carbon and (220) peak for platinum. 
Textural properties of carbon nanofibers such as specific surface area and pore volume were calculated from nitrogen adsorption-desorption isotherms, measured at $196{ }^{\circ} \mathrm{C}$ using a Micromeritics ASAP 2020. Total surface area and pore volume were determined using the Brunauer-Emmet-Teller (BET) equation and the single point method, respectively.

Electrical conductivity measurements were performed pressing the carbonaceous powder at $10 \mathrm{MPa}$ as described elsewhere [22]. The electrical resistance was measured applying electrical currents up to $20 \mathrm{~mA}$.

Energy dispersive X-ray (EDX) analyses and thermogravimetric analyses (TGA) in air were performed to quantify the metal loading in the Pt/CNF electrocatalysts. An EDX analyzer Röntec XFlash Si(Li) coupled to a Hitachi S-3400 N scanning electron microscope (SEM) was used. For TGA experiments in air, a Setaram Setsys Evolution thermogravimetric analyzer was used at atmospheric pressure, the temperature was varied between room temperature to $950^{\circ} \mathrm{C}$ with a rate of $5^{\circ} \mathrm{C} \mathrm{min}^{-1}$.

\subsection{Electrochemical experiments}

Gas diffusion electrodes were prepared according to a procedure described elsewhere [33]. Gas diffusion layer and the catalytic layer were laminated on carbon cloth backings. To reduce the flooding effects in the sulfuric acid half-cell, a hydrophobic backing layer was used (LT 1200W ELAT, E-TEK). The catalytic layer was composed of 33 wt.\% Nafion ${ }^{\circledR}$ ionomer and 67 wt.\% catalyst, with a Pt loading of ca. $0.15 \mathrm{mg} \mathrm{cm}^{-}$ $2\left( \pm 0.01 \mathrm{mg} \mathrm{cm}^{-2}\right)$.

Half-cell tests were carried out at $25^{\circ} \mathrm{C}$ in a conventional thermostated threeelectrode cell consisting on the gas diffusion electrode to be tested (working electrode), a mercury-mercurous sulfate reference electrode $\left(\mathrm{Hg} / \mathrm{Hg}_{2} \mathrm{SO}_{4}, \mathrm{~K}_{2} \mathrm{SO}_{4}\right.$ sat. $)$ and a high surface coiled platinum wire as counter electrode. The working electrode geometric area was $0.2 \mathrm{~cm}^{2}$, and a $0.5 \mathrm{M} \mathrm{H}_{2} \mathrm{SO}_{4}$ aqueous solution was employed as electrolyte. Gas (nitrogen or oxygen) was fed to the electrode backing layer during the tests. A $\mu$ Autolab Metrohm potentionstat/galvanostat was used to perform the measurements.

Among the various methods reported in literature [34], an accelerated stress test was selected for the evaluation of the catalysts resistance to degradation. It consisted on 
a continuous potential cycling between 0.6 and $1.2 \mathrm{~V}$ vs. RHE up to a total of 1,000 cycles, feeding nitrogen to the electrode. The evaluation of the decay process was carried out by in situ electrochemical tests: reference cyclic voltammetry (from 0.02 to $1.2 \mathrm{~V}$ vs. RHE) in nitrogen and polarization curves in pure oxygen. 


\section{Results and discussion}

Carbon nanofibers were synthesized at $700{ }^{\circ} \mathrm{C}(\mathrm{CNF})$ and successively treated (fCNF) in a nitric-sulfuric acids mixture at room temperature for 30 minutes. The main properties are summarized in Table 1. It is worth to point out that these CNFs present a low surface area (ca. $100 \mathrm{~m}^{2} \mathrm{~g}^{-1}$ ) when compared to conventional carbon blacks used as supports $\left(250 \mathrm{~m}^{2} \mathrm{~g}^{-1}\right)$ for fuel cell electrocatalysts. However, their highly graphitic character, denoted in terms of crystal size $\left(\mathrm{L}_{\mathrm{c}}\right)$ and intergraphene distance $(\mathrm{c} / 2)$, provides an indication of high resistance to electrochemical corrosion [21] and a high electrical conductivity [22]. When treated in nitric and sulfuric acids, the surface oxygen content increases to an almost two-fold level from $1.5 \mathrm{wt} . \%$ to $2.8 \mathrm{wt} \%$, preserving surface area and crystallinity, although pore volume increases and electrical conductivity (Elec. Conduc.) decreases after the oxidation treatment.

Platinum nanoparticles were deposited on the carbon nanofibers following four different procedures. The main properties of these catalysts are reported in Table 2. Both EDX and TGA measurements confirmed that platinum concentration was in all catalysts around $20 \pm 2 \mathrm{wt}$. $\%$, which is an optimum concentration for the relatively low surface area of the CNFs used along this work (ca. $100 \mathrm{~m}^{2} \mathrm{~g}^{-1}$ ). The platinum uptake is for CNFs considerably lower than for carbon blacks used in fuel cells. However, this metal concentration is compatible with the manufacturing of catalytic layers with low $\mathrm{Pt}$ loadings $\left(<0.2 \mathrm{mg} \mathrm{cm}^{-2}\right)$. The most important difference among the various deposition methods concerns with the Pt crystal size that is achieved for the catalyst, increasing in the order colloidal < microemulsion < impregnation $\left(\mathrm{NaBH}_{4}\right)<$ impregnation $(\mathrm{HCOOH})$, from $2.5 \mathrm{~nm}$ up to $8.1 \mathrm{~nm}$ (Table 2). Representative micrographs of catalyst morphology can be observed in Fig. 1.

The TEM micrographs show unimodal dispersion and moderate degree of agglomeration (Fig. 1). However, the average particle size was different for the various catalysts. Those catalysts showing the smaller particle size appeared to be more concentrated in metal. But, thermal analysis provided similar concentration results on an average basis. The theoretical mass surface areas (TMSA) were calculated according to a well known relationship [23]: 


$$
T M S A\left[m^{2} g^{-1}\right]=\frac{6000}{\rho_{P t}\left[\mathrm{~g} \mathrm{~cm}^{-3}\right] d_{P t}[\mathrm{~nm}]}
$$

where $\rho_{P t}$ is the density of platinum $\left(21.4 \mathrm{~g} \mathrm{~cm}^{-3}\right)$ and $d_{P t}$ (in $\left.\mathrm{nm}\right)$ is the average diameter of platinum particles considering spherical geometry.

The variation of TMSA indicates the expected variation of electrocatalytic activity, inversely to the variation of Pt particle size, as expected. Additionally, the theoretical average Pt-Pt interparticle distance $\left(D_{P t-P t}\right)$ was also calculated according to [24]:

$$
D_{P t-P t}=\frac{1}{3} \sqrt{\frac{\sqrt{3} \pi \rho_{P t} d_{P t}^{3} S_{B E T}\left(1-C_{P t}\right)}{C_{P t}}}
$$

where $\rho_{P t}$ and $d_{P t}$ are again the density of platinum and the average diameter, respectively, $S_{B E T}$ is the BET surface area of the support and $C_{P t}$ is the platinum mass concentration in the catalyst.

The values reported in Table 2 indicate that colloidal and microemulsion procedures lead to neighboring Pt particles much close than those corresponding to impregnation methods, which is also evidenced from TEM micrographs (Fig. 1).

X-ray diffraction patterns of the various catalysts are shown in Fig. 2. The main reflection of the hexagonal graphitic structure is clearly observed at $26^{\circ}$ two-theta, whereas Pt shows a face centered cubic structure with peak broadening decreasing when passing from colloidal to microemulsion and furthermore to impregnation methods. This reflects an increase of the mean crystallite size. The latter was calculated from the Scherrer equation and reported in Table 2.

IR-free Tafel plots for oxygen reduction are shown in Fig. 3. It is important to consider that these results have been obtained under flooded conditions, in sulfuric acid and at $25^{\circ} \mathrm{C}$. Thus, these performances are not directly comparable to those achievable 
in PEMFCs. However, the Tafel slope varies between 65 and $75 \mathrm{mV} \mathrm{dec}^{-1}$. This is similar to that recorded in PEMFCs, indicating similar oxygen adsorption isotherm and reduction mechanism [25].

The mass activity reaches a maximum for the catalyst with $3.4 \mathrm{~nm}$ Pt crystallite size in well accordance with the well known Kinoshita theory [26]. However, the volcano-shaped curve around $3 \mathrm{~nm}$ is not as sharp as the one reported by Kinoshita, indicating that also other parameters such as interparticle distance, degree of agglomeration or metal-support interaction play a relevant role. All these effects are governed by the preparation procedure with the microemulsion showing the best initial characteristics; the colloidal procedure causes the formation of small particles which are characterized by lower specific activity. This decrease in specific activity is not compensated by the increase of surface area. The very low surface area associated to the large particle size for the catalysts prepared by impregnation determines poor electrocatalytic activity. Formic acid is less strong as reducing agent than $\mathrm{NaBH}_{4}$ but the different reduction temperature $80^{\circ} \mathrm{C}$ vs $15^{\circ} \mathrm{C}$, respectively, causes the occurrence of larger particles in the catalyst prepared by using the organic reductant. This corresponds to a low performance.

A typical degradation test is shown in Fig. 4. It is clearly envisaged, for the colloidal catalyst, a decrease of current density associated to $\mathrm{Pt}-\mathrm{OH}$ formation and $\mathrm{Pt}-\mathrm{O}$ reduction waves. The Pt-O reduction peak also shows a shift towards higher potentials indicating an increase of intrinsic activity.

Fig. 5 shows for one catalyst a clear decrease of surface area. This decrease is quantified in Fig. 6 for the various catalysts. The decrease of surface area is proportional to the initial value of surface area. In other words, the decrease of surface area after the accelerated stress test is inversely related to the particle size. Interestingly, the decrease of mass activity follows the same trend only for catalysts with initial particle size larger than $3.4 \mathrm{~nm}$, as is shown in Fig. 7. The catalyst prepared by the colloidal method experiences a decrease of surface area due to the increase of particle size (Fig. 6). However, in terms of activity this is in part compensated by the increase of specific (intrinsic) activity. Thus, due to the sintering effect probably caused by an Ostwald ripening mechanism, the particle size of the colloidal catalyst increases passing through 
the optimal value. In other words, the better specific activity after degradation in part compensates for the decrease of surface area (Fig. 7). Similar evidences were observed in PEMFCs by Aricò et al. upon application of a similar accelerated stress test on a finely dispersed catalyst [27].

In the present work, it is clearly demonstrated that such a phenomenon occurs for catalysts with an initial particle size smaller than the optimal one in the volcanoshaped curve. As further evidence of this increase of intrinsic activity, which in part compensates for the decrease of surface area, there is the positive shift of the Pt-O reduction peak in the cyclic voltammograms (Fig. 5).

These results clearly suggest that the catalyst should not be optimized with the aim to achieve the highest possible initial performance but also with regard to durability aspects and the achievement of a suitable catalytic activity after prolonged operation. Catalysts characterized by small particle size are usually considered more prompt to sintering and dissolution. However, the performance may remain suitable over long periods especially if they are dispersed on a stable carbon nanofiber support such as the one used in the present work. 


\section{Conclusions}

Four preparation methods were investigated to obtain small Pt particles on a low BET surface area carbon support consisting of cost-effective carbon nanofibers. Colloidal and microemulsion methods showed proper capability to produce catalysts with mean Pt crystallite size below $3.5 \mathrm{~nm}$. The choice of a low BET surface area carbon nanofiber support was prompted by the need of mitigating carbon support corrosion in fuel cell applications. A mesoporous structure of CNF appears relevant to reduce mass transport constraints. The high graphitic character is another interesting property of this material.

A volcano-shaped relationship was observed for ORR mass activity as a function of the particle size for CNF-supported Pt nanoparticles similar to what demonstrated by Kinoshita for carbon black supported Pt catalysts.

Upon applying accelerated degradation tests, the corresponding decrease of electrochemically active surface area was directly related to the initial catalyst surface area, or in other words, inversely related to the initial Pt particle size.

The corresponding decrease of mass activity after the accelerated degradation tests was following the same trend of surface area decrease, only for catalysts with initial particle size above $3.4 \mathrm{~nm}$ (right branch of volcano-shaped curve of mass activity vs. particle size). Whereas, for the catalyst characterized by very small initial particle size (left branch of volcano-shaped curve), the decrease of mass activity was much less than that expected by the decrease of electrochemical surface area. This is interpreted by considering that particle sintering growth phenomena occurring during the ADT allow the catalyst to achieve a slightly larger particle size corresponding to a better specific (intrinsic) activity. This is confirmed by cyclic voltammetry analysis. Such evidence suggests the need to tailor the initial catalyst characteristics as a function of the planned operating life of the fuel cell device. 


\section{Acknowledgements}

The authors wish to thank FEDER and the Spanish MEC for financial support to project CTQ2011-28913-C02-01. The authors also acknowledge the support of bilateral CNR (Italy) -CSIC (Spain) joint agreement 2011-2012 (project Baglio/Lazaro 2010IT0026). 


\section{References}

[1] E. Antolini, Appl. Catal. B: Environ. 88 (2009) 1-24.

[2] V. Baglio, A. Di Blasi, C. D’Urso, V. Antonucci, A. S. Aricò, R. Ornelas, D. Morales-Acosta, J. Ledesma-Garcia, L. A. Godinez, L. G. Arriaga, L. AlvarezContreras, J. Electrochem. Soc. 155 (2008) B829-B833.

[3] D. Sebastián, M.J. Lázaro, I. Suelves, R. Moliner, V. Baglio, A. Stassi, A.S. Aricò, Int. J. Hydrogen Energy 37 (2012) 6253-6260.

[4] H. Huang, H. Chen, D. Sun, X. Wang, J. Power Sources 204 (2012) 46-52.

[5] R. Awasthi, R.N. Singh, Int. J. Hydrogen Energy 37 (2012) 2103-2110.

[6] M.H. Al-Saleh, U. Sundararaj, Carbon 47 (2009) 2-22.

[7] S. Song, P. Tsiakaras, Appl. Catal. B: Environ. 63 (2006) 187-193.

[8] V. Di Noto, E. Negro, Electrochim. Acta 55 (2010) 7564-7574.

[9] S. Song, Y. Liang, Z. Li, Y. Wang, R. Fu, D. Wu, P. Tsiakaras, Appl. Catal. B: Environ. 98 (2010) 132-137.

[10] S. Song, Y. Wang, P. Tsiakaras, P.K. Shen, Appl. Catal. B: Environ. 78 (2008) 381-387.

[11] J. Zeng, C. Francia, C. Gerbaldi, M.A. Dumitrescu, S. Specchia, P. Spinelli, J. Solid State Electrochem. 16 (2012) 3087-3096.

[12] T. Kottakkat, A.K. Sahu, S.D. Bhat, P. Sethuraman, S. Parthasarathi, Appl. Catal. B: Environ. 110 (2011) 178-185.

[13] V. Di Noto, E. Negro, Fuel Cells 10 (2010) 234-244.

[14] I. Kvande, S.T. Briskeby, M. Tsypkin, M. Ronning, S. Sunde, R. Tunold, D. Chen, Top. Catal. 45 (2007) 81-85.

[15] I. Kvande, J. Zhu, T.J. Zhao, N. Hammer, M. Ronning, S. Raaen, J.C. Walmsley, D. Chen, J. Phys. Chem. C 114 (2010) 1752-1762. 
[16] A.S. Aricò, P.L. Antonucci, E. Modica, V. Baglio, H. Kim, V. Antonucci, Electrochim. Acta 47 (2002) 3723-3732.

[17] H.A. Gasteiger, S.S. Kocha, B. Sompalli, F.T. Wagner, Appl. Catal. B: Environ. 56 (2005) 9-35.

[18] T.G. Ros, A.J. van Dillen, J.W. Geus, D.C. Koningsberger, ChemPhysChem 3 (2002) 209-214.

[19] A.S. Aricò, P.L. Antonucci, V. Antonucci, in: A. Wieckowski, E.R. Savinova, C.G. Vayenas, Catalysis and Electrocatalysis at Nanoparticle Surfaces, Marcel Dekker, Inc., New York, 2003, p. 613.

[20] J.C. Calderón, N. Mahata, M.F.R. Pereira, J.L. Figueiredo, V.R. Fernandes, C.M. Rangel, L. Calvillo, M.J. Lázaro, E. Pastor, Int. J. Hydrogen Energy 37 (2012) 7200-7211.

[21] D. Sebastián, A.G. Ruiz, I. Suelves, R. Moliner, M.J. Lázaro, V. Baglio, A. Stassi, A.S. Aricò, Appl. Catal. B: Environ. 115-116 (2012) 269-275.

[22] D. Sebastián, I. Suelves, R. Moliner, M.J. Lázaro, Carbon 48 (2010) 4421-4431.

[23] O. Stonehart, J. Appl. Electrochem. 22 (1992) 995-1001.

[24] M. Watanabe, H. Sei, P. Stonehart, J. Electroanal. Chem. 261 (1989) 375-387.

[25] A. Stassi, I. Gatto, G. Monforte, V. Baglio, E. Passalacqua, V. Antonucci, A.S. Aricò, J. Power Sources 208 (2012) 35-45.

[26] K. Kinoshita, J. Electrochem. Soc. 137 (1990) 845-848.

[27] A.S. Aricò, A. Stassi, E. Modica, R. Ornelas, I. Gatto, E. Passalacqua, V. Antonucci, J. Power Sources 178 (2008) 525-536.

[28] W.H. Lizcano-Valbuena, V.A. Paganin, E.R. González, Electrochim. Acta 47 (2002) 3715-3722.

[29] J.R.C. Salgado, E. Antolini, E.R. González, J. Phys. Chem. B 108 (2004) 1776717774. 
[30] J. Solla-Gullón, F.J. Vidal-Iglesias, V. Montiel, A. Aldaz, Electrochim. Acta 49 (2004) 5079-5088.

[31] S. Eriksson, U. Nylén, S. Rojas, M. Boutonnet, Appl. Catal., A 265 (2004) 207219.

[32] A.S. Aricò, V. Baglio, A. Di Blasi, E. Modica, P.L. Antonucci, V. Antonucci, J. Electroanal. Chem. 557 (2003) 167-176.

[33] V. Baglio, A. Di Blasi, A.S. Aricò, V. Antonucci, P.L. Antonucci, F. Nannetti, V. Tricoli, Electrochim. Acta 50 (2005) 5181-5188.

[34] R. Borup, J. Meyers, B. Pivovar, Y.S. Kim, R. Mukundan, N. Garland, D. Meyers, M. Wilson, F. Garzon, D. Wood, P. Zelenay, K. More, K. Stroh, T. Zawodzinski, J. Boncella, J.E. McGrath, M. Inaba, K. Miyatake, M. Hori, K. Ota, Z. Ogumi, S. Miyata, A. Nishikata, Z. Siroma, Y. Uchimoto, K. Yasuda, K. Kimijima, N. Iwashita, Chem. Rev. 107 (2007) 3904-3951. 


\section{Captions to figures}

Figure 1. TEM images of (a) Pt/fCNF-IFA; (b) Pt/fCNF-ISB; (c) Pt/CNF-MIC; (d) $\mathrm{Pt} / \mathrm{CNF}-\mathrm{COL}$.

Figure 2. XRD patterns of the different Pt/CNF catalysts.

Figure 3. Tafel plots in half-cell, pure oxygen at $25^{\circ} \mathrm{C}$ and $0.5 \mathrm{M} \mathrm{H}_{2} \mathrm{SO}_{4}$.

Figure 4. Accelerated degradation test by potential cycling for the catalyst Pt/CNFCOL. 1,000 cycles in $0.5 \mathrm{M} \mathrm{H}_{2} \mathrm{SO}_{4}$ at $25^{\circ} \mathrm{C}$.

Figure 5. Cyclic voltammograms in $0.5 \mathrm{M} \mathrm{H}_{2} \mathrm{SO}_{4}$ before and after the accelerated degradation test (ADT) for Pt/CNF-COL.

Figure 6. Electrochemical surface area variation with the accelerated degradation test for Pt/CNF catalysts.

Figure 7. Variation of mass activity in the activation controlled region ( $0.8 \mathrm{~V}$ vs. RHE) for $\mathrm{Pt} / \mathrm{CNF}$ catalysts before and after ADT. 
Table 1. Supports physico-chemical properties.

\begin{tabular}{ccccccc}
\hline Support & $\begin{array}{c}\mathrm{S}_{\mathrm{BET}} \\
\left(\mathrm{m}^{2} \mathrm{~g}^{-1}\right)\end{array}$ & $\begin{array}{c}\text { Pore vol. } \\
\left(\mathrm{cm}^{3} \mathrm{~g}^{-1}\right)\end{array}$ & $\begin{array}{c}\mathrm{L}_{\mathrm{c}} \\
(\mathrm{nm})\end{array}$ & $\begin{array}{c}\mathrm{C} / 2 \\
(\mathrm{~nm})\end{array}$ & $\begin{array}{c}\text { Oxygen } \\
\text { content } \\
(\text { wt.\%) }\end{array}$ & $\begin{array}{c}\text { Elec. } \\
\text { Cond. (a) } \\
\left(\mathrm{S} \mathrm{cm}^{-1}\right)\end{array}$ \\
\hline $\mathrm{CNF}$ & 97 & 0.21 & 10.7 & 0.336 & 1.5 & 3.45 \\
$\mathrm{fCNF}$ & 101 & 0.38 & 9.9 & 0.339 & 2.8 & 1.67 \\
\multicolumn{2}{l}{ (a) Measured at a compaction degree equivalent to an apparent density of $0.80 \mathrm{~g} \mathrm{~cm}^{-3}$, non } \\
optimized conditions.
\end{tabular}


Table 2. Pt/CNF catalyst properties.

\begin{tabular}{cccccc}
\hline Catalyst & $\begin{array}{c}\text { Protocol+ } \\
\text { Reduction }\end{array}$ & $\begin{array}{c}\text { Pt crystal size } \\
(\mathrm{nm})\end{array}$ & $\begin{array}{c}\text { Pt conc. } \\
(\mathrm{wt} . \%)\end{array}$ & $\begin{array}{c}\mathrm{TMSA}^{(\mathrm{a})} \\
\left(\mathrm{m}^{2} \mathrm{~g}^{-1}\right)\end{array}$ & $\begin{array}{c}\text { Pt-Pt distance } \\
(\mathrm{nm})\end{array}$ \\
\hline Pt/fCNF-IFA & $\begin{array}{c}\text { Impregn.+ } \\
\text { HCOOH }\end{array}$ & 8.1 & $18 \pm 2$ & 34 & 55 \\
Pt/fCNF-ISB & $\begin{array}{c}\text { Impregn.+ } \\
\text { NaBH }\end{array}$ & 6.8 & $19 \pm 2$ & 40 & 41 \\
Pt/CNF-MIC & $\begin{array}{c}\text { Microemul.+ } \\
\mathrm{NaBH}_{4}\end{array}$ & 3.4 & $19 \pm 2$ & 81 & 15 \\
Pt/CNF-COL & $\begin{array}{c}\text { Colloidal+H } \\
\text { (a) }\end{array}$ & 2.5 & $18 \pm 2$ & 110 & 10 \\
\hline & Theoretical mass surface area calculated from equation 1.
\end{tabular}


Figure 1.
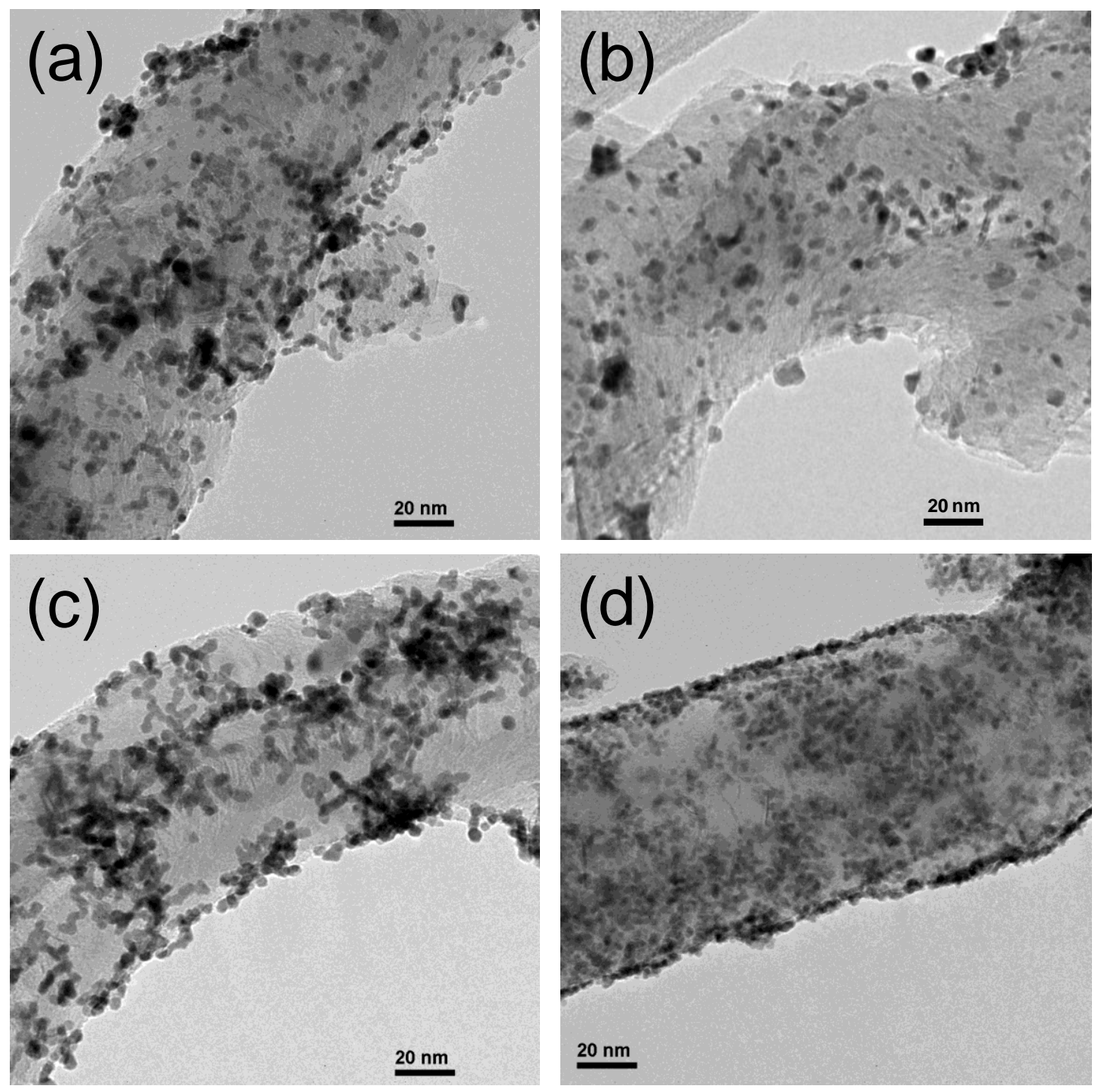
Figure 2.

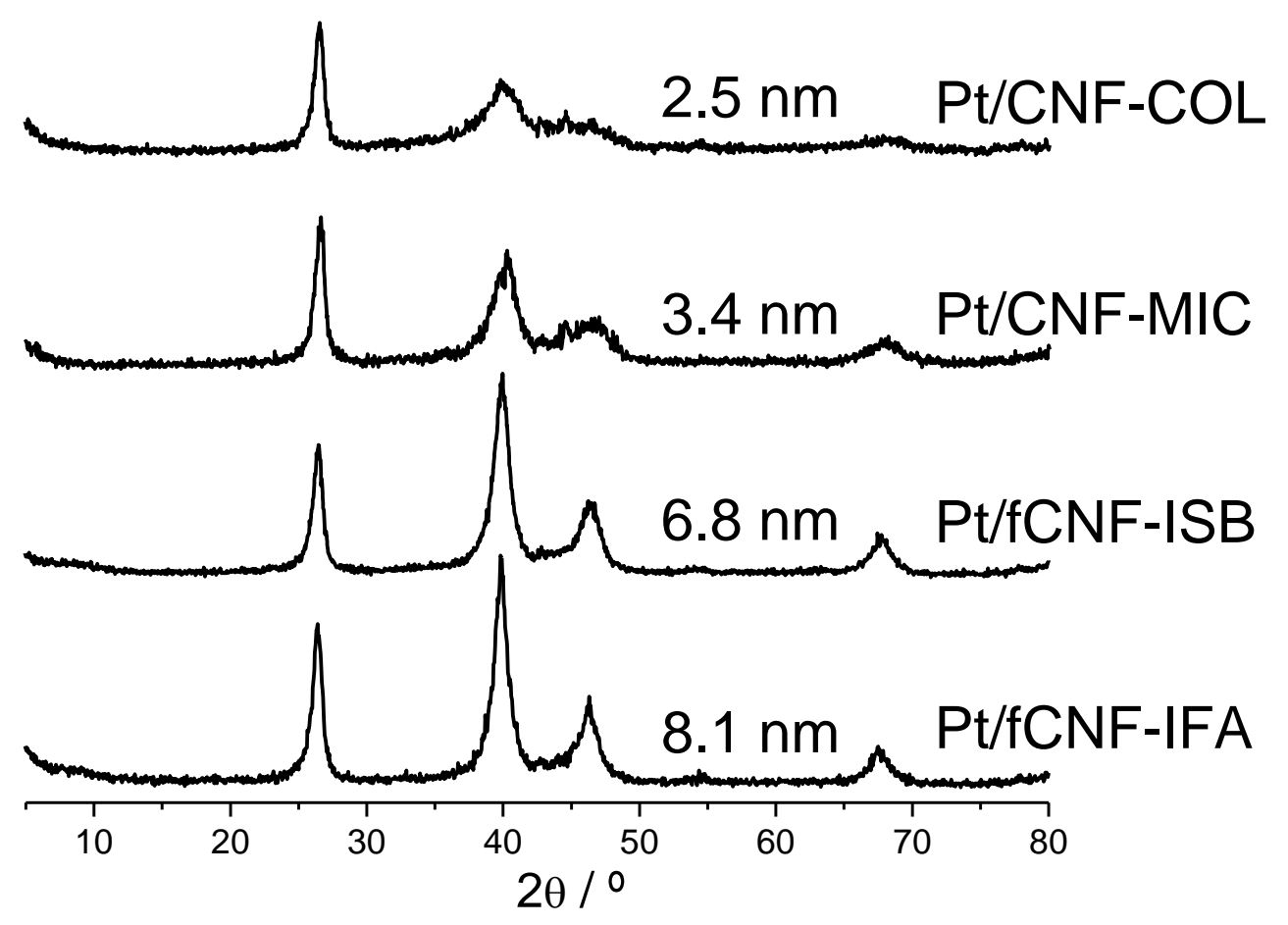


Figure 3.

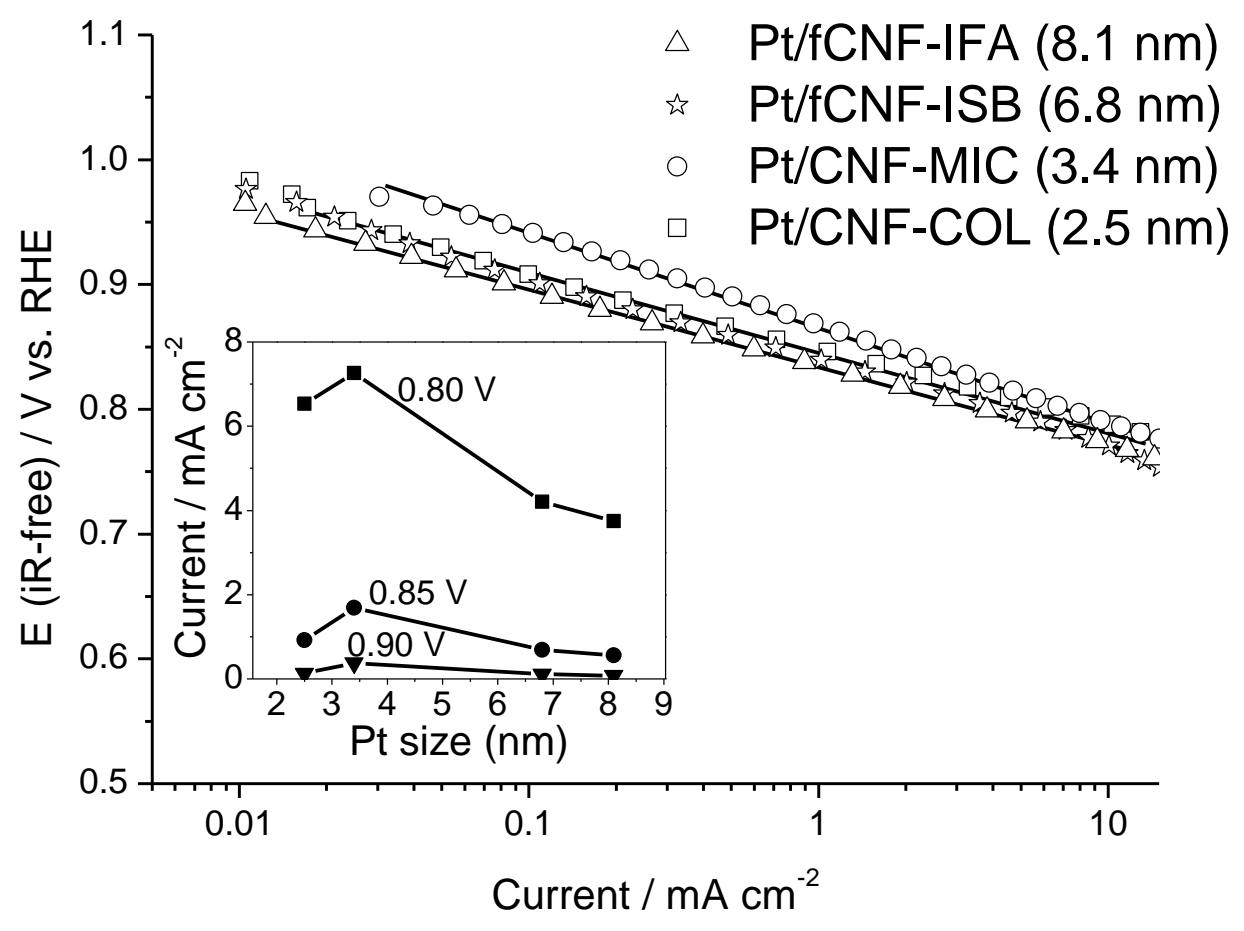


Figure 4.

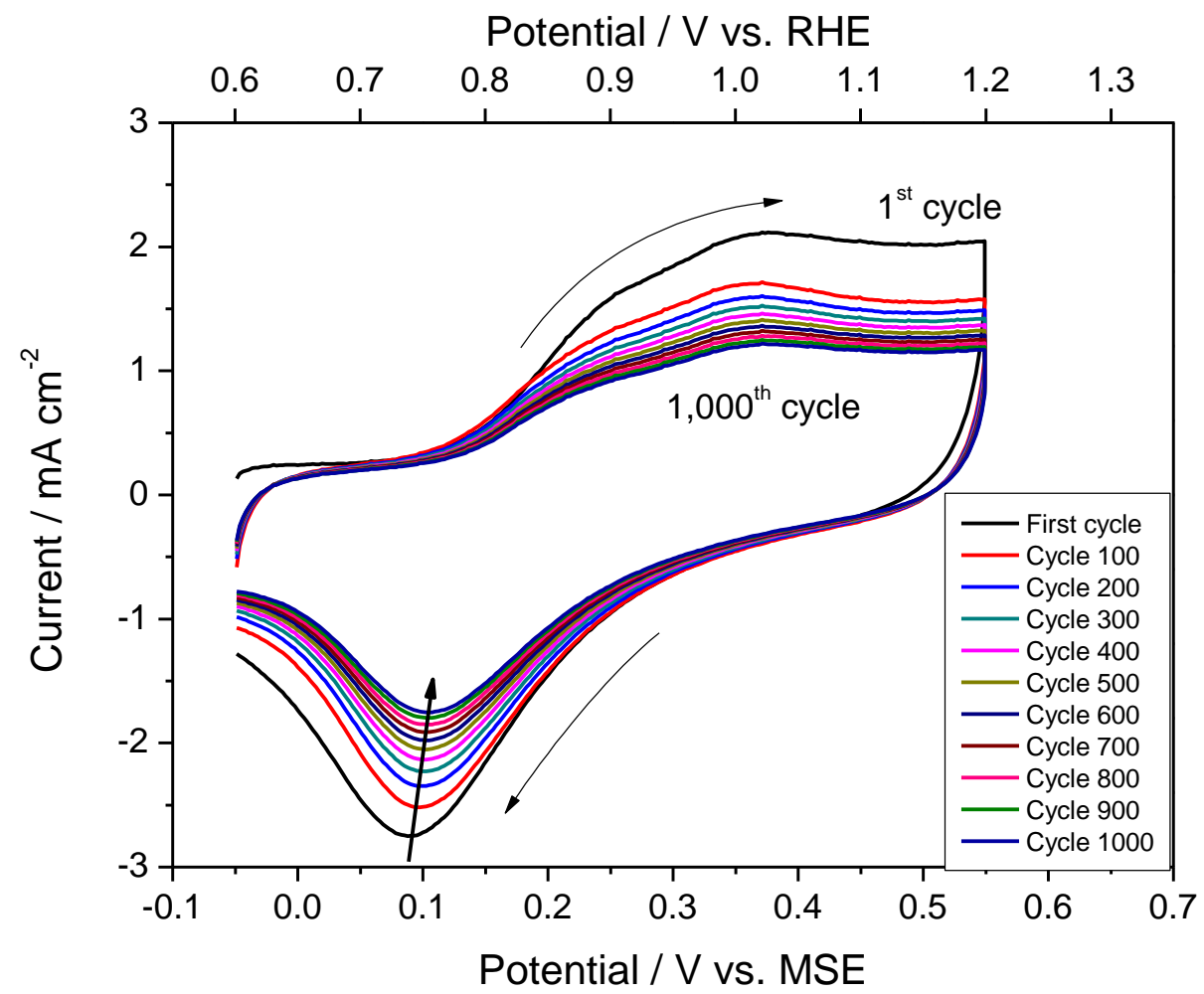


Figure 5.

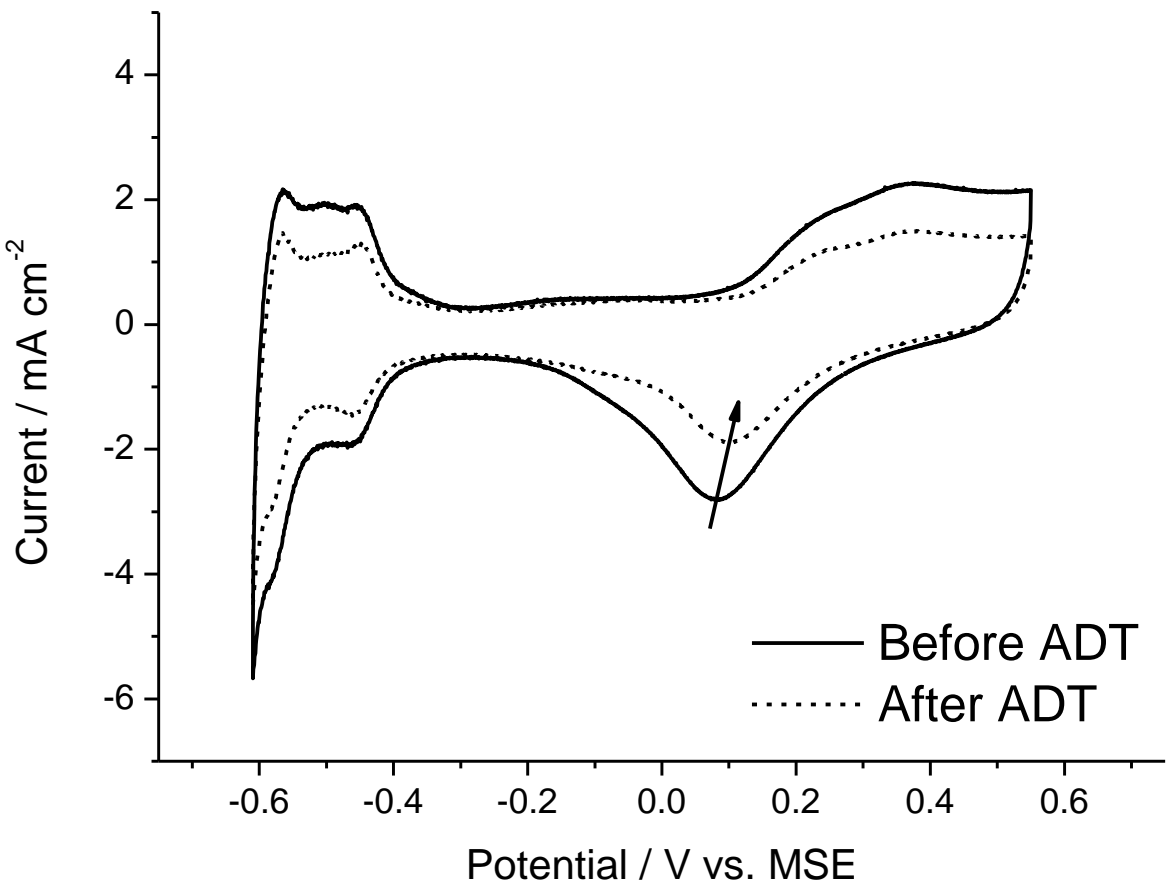


Figure 6.

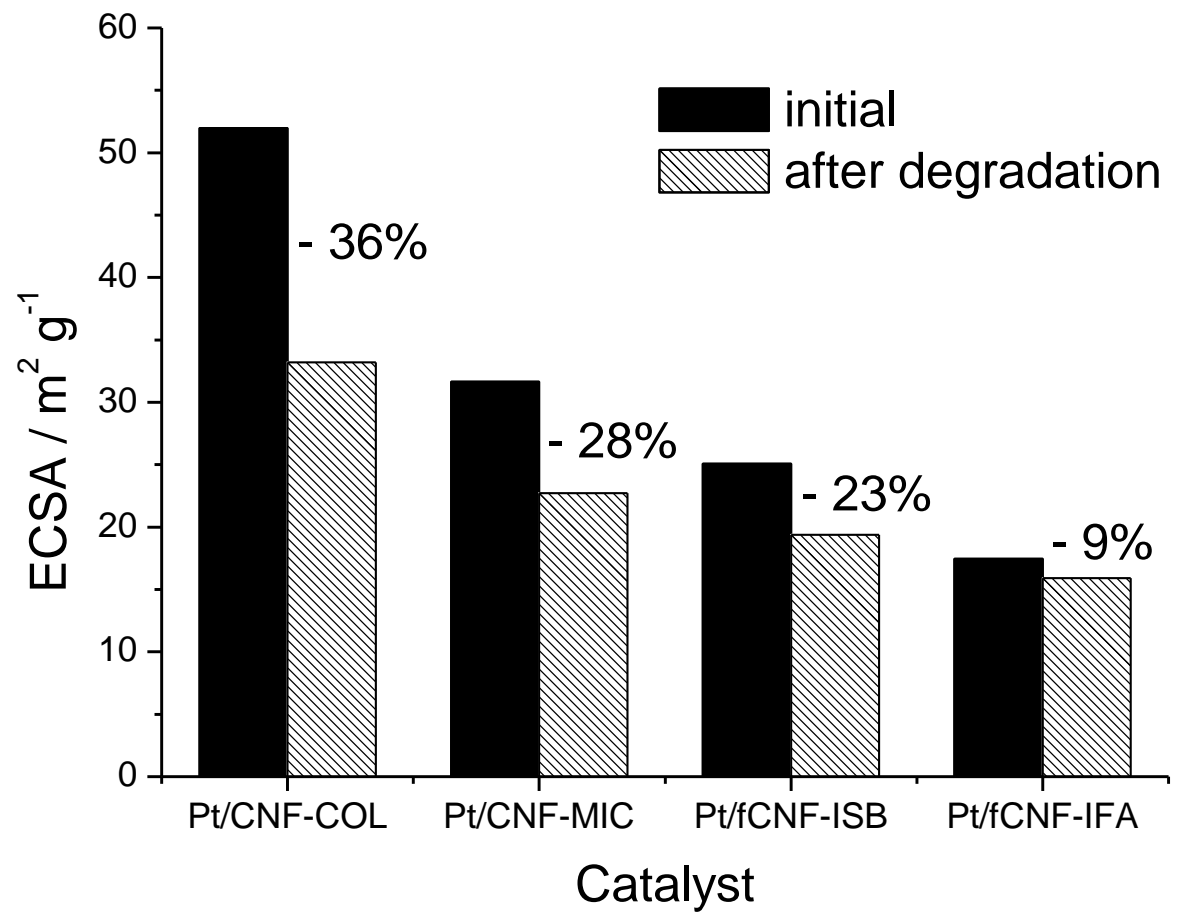


Figure 7.

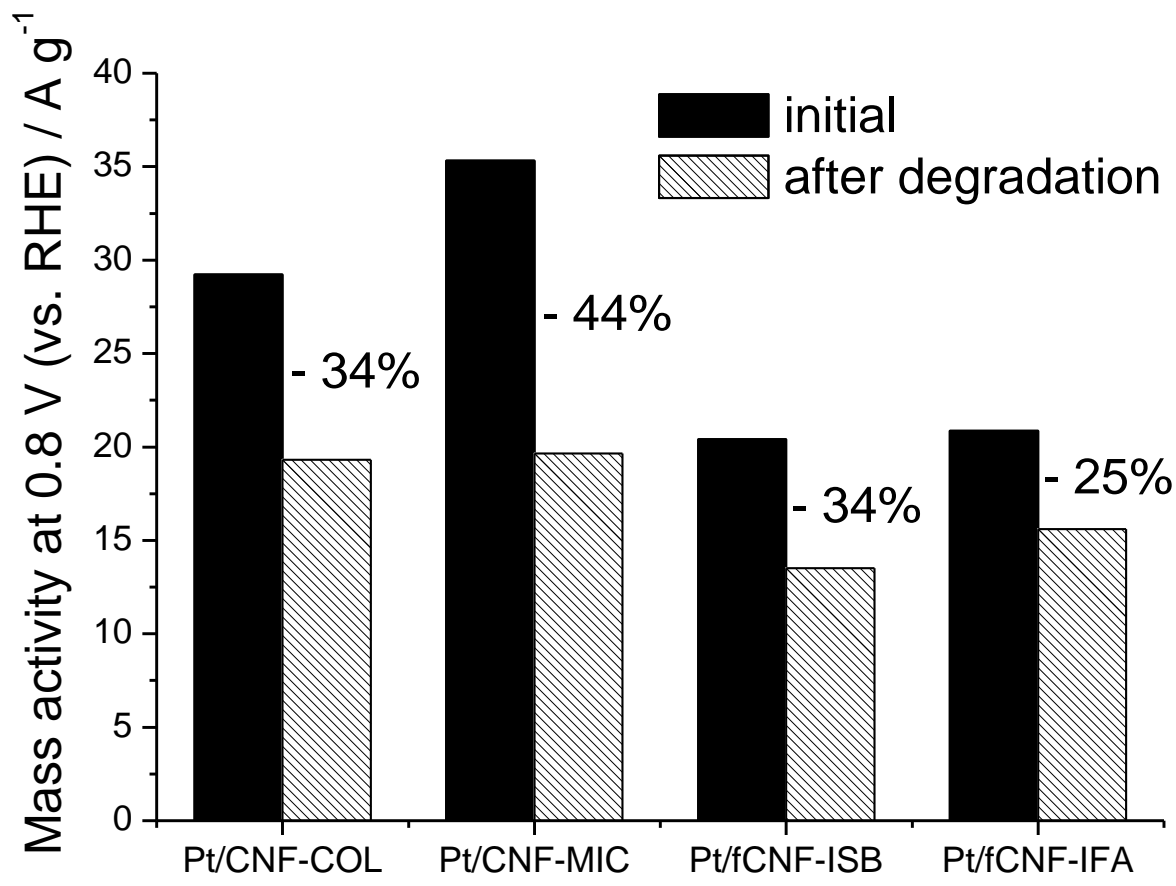

Catalyst 


\section{${ }^{*}$ Graphical Abstract (for review)}

\section{Graphical abstract}

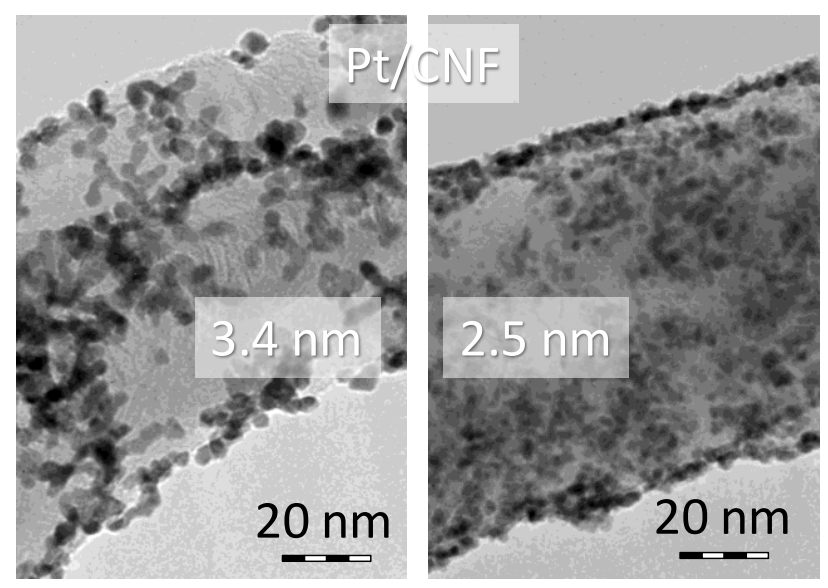




\section{Highlights}

- Synthesis of Pt catalyst on low surface area CNF was optimized using four methods

- Colloidal and microemulsion were appropriate methods to obtain small $\mathrm{Pt}$ particles

- A volcano-shaped curve was obtained for ORR mass activity vs. Pt particle size

- Degradation tests highlighted the need for initial Pt particles smaller than $3 \mathrm{~nm}$ 